\title{
Bacterial Protease Inhibitors as Antibacterial agents to prevent Bacterial Infections Associated with Biofilms
}

$$
\text { *Sarah } \mathbf{S}^{1} \text { and Shanmugaraju, } \mathbf{V}^{\mathbf{2}}
$$

${ }^{1}$ Research scholar, Department of Biotechnology, Dr.NGP College of Arts and Science, Coimbatore, Tamil Nadu, India, 9585719367, sarah.selvaraj@gmail.com

${ }^{2}$ Principal, E.S. Arts and Science College (Co-Ed), Ellis Chatram, Villupuram, Tamil Nadu, India 9894092682, rajugenes@gmail.com

*Corresponding author

${ }^{1}$ Research scholar, Department of Biotechnology, Dr.NGP College of Arts and Science, Coimbatore, Tamil Nadu, India

$$
9585719367
$$

sarah.selvaraj@gmail.com 


\begin{abstract}
Isolation of protease inhibitor producing bacteria from microbial mat and investigating its anti-biofilm potential against biofilm producing organism was selected as the main objective of the present study. Protease inhibitor (PI) was produced from bacterial isolates and purified using ammonium sulphate precipitation methods. Primary and secondary protease inhibitor assay was carried out separately to confirm the inhibition of protease enzyme activity both qualitatively and quantitatively. Antibacterial activity and anti-biofilm assay was performed to determine the biofilm prevention capabilities of PI. Three isolates $\left(\mathrm{B}_{1} \mathrm{PI}, \mathrm{B}_{2} \mathrm{PI}\right.$ and $\left.\mathrm{B}_{3} \mathrm{PI}\right)$ were screened and $\mathrm{B}_{2} \mathrm{PI}$ bacterial culture was selected based on the results of primary and secondary protease inhibitor assay. Maximum trypsin inhibition of $77.5 \pm 0.25 \%$ was recorded for the isolate $\mathrm{B}_{2} \mathrm{PI}$. Antibacterial activity of the $\mathrm{B}_{2} \mathrm{PI}$ protease inhibitor fractions exhibited inhibitory zones of $22.3 \pm 1.04 \mathrm{~mm}$ and $20.2 \pm 0.25 \mathrm{~mm}$ against Escherichia coli and Staphylococcus aureus respectively. Anti-biofilm assay of protease inhibitor fractions expressed $31.2 \mu \mathrm{l} / \mathrm{ml}$ of MBIC against Escherichia coli and Staphylococcus aureus. The results conclude that, the protease inhibitor from the microbial mat isolate will be an effective alternative to the commercial antibiotics either alone or in combination with other drugs synergistically which shall be studied elaborately in future.
\end{abstract} Keywords: Microbial mat, Protease inhibitor, Biofilm, Trypsin, Anti-biofilm 


\section{INTRODUCTION}

Specific inhibition of these proteases can be used as a strategy for drug designing. In medicine, protease inhibitors can be used as diagnostic or therapeutic agents for viral, bacterial, fungal and parasitic diseases as well as for treating cancer and immunological, neurodegenerative and cardiovascular diseases (Hamilton et al., 2001). Proteases are potentially hazardous to their proteinaceous environment and their activities need to be kept strictly under control. Microbial proteases have been recognized as virulence factors in a variety of diseases caused by microorganisms. These enzymes have also been responsible to degrade proteins that function in host defense in vivo (Sakata et al., 1993). In the light of rapidly spreading antibiotic resistance, bacterial proteases are promising targets for the design of novel antibiotics (Sabotic and Kos, 2012). Enzyme inhibitors are agents that combine with an enzyme in such a manner as to slow down or prevent the catalytic action of the enzyme. Enzyme inhibitors are important as therapeutic agents, as regulators in controlling the enzymic processes in living organisms (Robert et al., 2012). They are protein degrading enzymes that catalyze the cleavage of peptide bonds in proteins and perform essential metabolic and regulatory functions in many biological processes (Turk, 2006).

The search for novel types of microbial inhibitors from natural marine and terrestrial sources are important for identifying new lead compounds (Sabotic and Kos, 2012). Protease inhibitors of microbial origin have been studied and already proven useful in many different applications (Rawlings, 2010; Rawlings and Barrett, 2011). Microbial mats are considered as one such natural source which contains diverse populations of prokaryotic organisms as well as eukaryotic organisms and other unicellular algae (Donlan, 2001). Mats are ubiquitous in nature, commonly found over the sediment surfaces or as floating masses in fresh waters, marine water, soils, rainy muds and hydrothermal vents (Madigan et al., 2000). Organisms associated with these mats can thrive on extreme conditions by synthesizing their own biological compounds (Wong and Visscher, 2015).

Based on this concept, protease inhibitors of microbial origin were investigated from the isolates of microbial mats in the present research. As an application study, the effect of protease inhibitor on the biofilm formation of bacterial pathogens was also investigated. Biofilms formed by the pathogens are resistant to many of the antimicrobial agents commonly used (Prasad et al., 2016). Previous reports suggest that protease inhibitors specifically, inhibitors of sesrine and aspartyl proteases are effective antibiofilm agents (Skrbec and Romeo, 2002). Hence in the present study, isolation of protease inhibitor 
producing bacteria from microbial mat and investigating its anti-biofilm potential against medically significant biofilm producing organism was considered as the primary objectives. Detailed study of novel protease inhibitors from the natural microbial mats will provide the basis for future research.

\section{MATERIALS AND METHODS}

The present research work was carried out in the Department of Biotechnology, Dr.NGP College of Arts and Science, Coimbatore, Tamil Nadu, India. The work was done during the period of November 2020 to February 2020.

\section{Collection and processing of Microbial mats}

Microbial mats were selected from the natural source during heavy rain periods. The samples were collected on the second day after rain stopped. The terrestrial mats were collected from the garden area of the institution in a sterile zip-lock covers using spatula and glass petri dish. The collected terrestial mats were stored under refrigeration condition prior processing.

\section{Isolation of bacteria from microbial mats (Charlesworth et al., 2019)}

Microorganisms were isolated from the sediment using Soil Extract Agar media [Glucose 1.0g/l, Dipotassium phosphate 0.5g/l, Soil extract 17.75g/l and Agar 15.0g/l. Final $\mathrm{pH}$ ( at $25^{\circ} \mathrm{C}$ ) $6.8 \pm 0.2$ ] by pour plating of serially diluted samples. After incubation, the isolated colonies were picked and purified by single colony plating technique.

\section{Screening the isolates for PI production using Protease inhibitor assay (Imada, 2004)}

Protease inhibitor assay was carried out using plate assay method. The method was performed for the detection of protease inhibitor in Skim Milk Agar plate. The purified fractions containing PI was added in the media $\left(36 \pm 2^{\circ} \mathrm{C}\right)$ before pouring onto the plates. The media was immediately poured and allowed to solidify at room temperature. Similarly another set of skimmed milk agar plates were prepared without PI (control). Using sterile conditions $6 \mathrm{~mm}$ well was made in the centre of the skimmed milk agar plate. Twenty microlitre of $0.5 \mathrm{mg} / \mathrm{mL}$ trypsin (as protease enzyme) was added in the well of both test and control plates. All the PI added plates were incubated at $37^{\circ} \mathrm{C}$ to observe the inhibition of casein hydrolysis. And the plates without PI were incubated to observe the casein hydrolysis due to the action of trypsin in the well. The PI extracted from the isolates inhibiting the casein hydrolysis was selected as the significant organism of microbial mat origin. To confirm the 
effect of PI screened, caseinolytic broth assay was performed as the secondary screening method.

\section{Protease inhibitor (PI) production from selected isolate (Leung et al., 2000)}

A loopful of cells from the freshly grown stock culture slants were transferred to a $10 \mathrm{~mL}$ Casein broth incubated at room temperature $\left(28 \pm 2^{\circ} \mathrm{C}\right)$ for $18 \mathrm{~h}$ with constant shaking at $120 \mathrm{rpm}$ on a rotary shaker. After incubation, this pre-culture was transferred to a $50 \mathrm{ml}$ production media containing trypsin as substrate. The media were incubated at room temperature $\left(28 \pm 2^{\circ} \mathrm{C}\right)$ with constant shaking at $120 \mathrm{rpm}$ on a rotary shaker. After $48 \mathrm{~h}$ incubation the broth was centrifuged at $10,000 \mathrm{rpm}$ for $15 \mathrm{~min}$ at $4^{\circ} \mathrm{C}$. This cell free supernatant was used as crude protease inhibitor (PI).

\section{Purification of protease inhibitor (Wahyudi et al., 2010)}

The crude PI samples were purified using standard Ammonium sulphate precipitation. Ammonium sulphate (Hi Media) required to precipitate the protease inhibitor was optimized using $30 \%$ saturation to the crude extract. After complete dissolution of ammonium sulphate, the solution was kept for precipitation at $4^{\circ} \mathrm{C}$ for $4 \mathrm{~h}$. Protein precipitated was collected by centrifugation at $10,000 \mathrm{rpm}$ for $15 \mathrm{~min}$ at $4^{\circ} \mathrm{C}$. The precipitate obtained after ammonium sulphate precipitation was further dialyzed against $0.01 \mathrm{M}$ phosphate buffer $(\mathrm{pH} 7.5)$, in order to remove the ammonium sulphate from the precipitate. Purified fractions were finally screened for protease inhibitor assay.

\section{Secondary Protease inhibitor (PI) assay (Imada, 2004)}

Secondary Protease inhibitor (PI) assay was performed using Caseinolytic broth assay method. Briefly, fifty microlitre of trypsin (as protease enzyme) in $0.6 \mathrm{ml}$ of $30 \mathrm{mM}$ Tris- $\mathrm{HCl}$ buffer ( $\mathrm{pH} \mathrm{7.0)}$ ) was mixed with $0.6 \mathrm{ml}$ of purified fractions of purified PI for $10 \mathrm{~min}$ at $28^{\circ} \mathrm{C}$. One $\mathrm{ml}$ of $1 \%$ casein in the mixture was added and incubated for $10 \mathrm{~min}$ at $28 \pm 2^{\circ} \mathrm{C}$. About $5 \mathrm{ml}$ of $10 \%$ trichloroacetic acid was added to terminate the enzyme-substrate (trypsin-casein) reaction and mixture was kept for $15 \mathrm{~min}$ at $28 \pm 2^{\circ} \mathrm{C}$. The mixture was centrifuged at $5000 \mathrm{rpm}$ for $10 \mathrm{~min}$. The optical density of filtrate was measured by turbidometric measurement at $260 \mathrm{~nm}$ in a UV-Vis spectrophotometer. Optical density of the blank and control (without PI) were also collected. One unit of inhibitor activity was defined as the amount by which enzyme activity was reduced by $50 \%$. 
The percentage of inhibition was calculated as

\section{Protease Inhibition $(\%)=1-$ B / A X 100}

where, A was the optical density of sample (without inhibitor), and B was the optical density of sample (with inhibitor).

\section{Antibacterial activity of PI against biofilm producing bacteria (Gulati et al., 2018)}

The antibacterial activity of purified fractions of PI was evaluated against biofilm producing bacterial species using Agar well diffusion method. Sterile Muller-Hinton agar plates were prepared. The plates were allowed to solidify for 5 minutes and wells of $6 \mathrm{~mm}$ were punctured using a well borer. $0.1 \%$ inoculum suspension of each test organisms (Escherichia coli Staphylococcus albus and Citrobacter sp) was swabbed uniformly over the

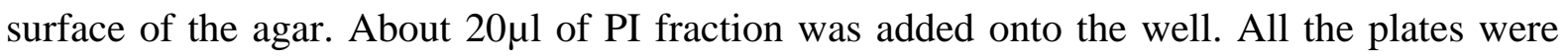
incubated at $37^{\circ} \mathrm{C}$ for 24 hours. Zone of inhibition around the well was measured after incubation and recorded.

\section{Anti-biofilm assay of PI against biofilm producers (Schillaci et al., 2008)}

Anti-biofilm properties of protease inhibitor were determined using Sustained Inhibition assay against the test organisms. The procedure contains two series of bacterial adherence phase on the microtitre plate surface. PI was added during the first 90-minute adherence phase.

Briefly, $100 \mu 1$ of protease inhibitor at different concentrations $(15.6-100 \mu 1 / \mathrm{ml})$ and standard drug, ofloxacin in concentration $7.8-100 \mu \mathrm{l} / \mathrm{ml}$ in sterile TSB medium with $1 \%$ glucose was added to selected wells of a 96-well microtiter plate, seeded with $100 \mu 1$ of a suspension that contained $10^{8}$ cells $/ \mathrm{ml}$, and incubated for $24 \mathrm{~h}$ at $37^{\circ} \mathrm{C}$ to allow biofilm formation. The contents of the wells were aspirated and washed three times in sterile PBS. The extent of biofilm formation was assessed by the MTT reduction assay as described by Schillaci et al. (2008). The results are expressed as the minimal biofilm inhibitory concentration (MBIC) compared with the control (without treatment) for the MTT assays.

\section{RESULTS AND DISCUSSION}

\section{Collection and processing of Microbial mats}

Microbial mats selected from the natural source after rain stopped is presented in Fig.1a and Fig.1b. Mats appeared bluish green with brown coloured top surface indicating the growth of several types of soil microbes. As the mats were found sustaining in the natural 
environment, soil microbes would form a microbial consortium with the aid of their native soil enzymes.

\section{Isolation of bacteria from microbial mats (Charlesworth et al., 2019)}

Microorganisms isolated from the microbial mat sediments in the Soil Extract Agar media by pour plating of serially diluted samples were presented in Fig. $2 a, 2 b$ and $2 c$. The isolated colonies were picked and purified by single colony plating technique. The isolated cultures were maintained in Nutrient Agar media slants at $4{ }^{\circ} \mathrm{C}$. Six isolates based on the colony morphology and colour were selected randomly for the screening tests.

\section{Screening the isolates for PI production using Protease inhibitor assay}

Among the six isolates, $1 \mathrm{~A}$ and $1 \mathrm{~B}$ are selected based on the obtained results presented in Table-1. No casein hydrolysis was evident around the colonies of 1A and 1B. This results showed that isolates were capable of producing protease inhibitor. Other isolates, $1 \mathrm{C}, 1 \mathrm{D}, 1 \mathrm{E}$ and $1 \mathrm{~F}$ are considered as non PI producing isolates as the casein hydrolysis was significantly found evident (Fig. 3). The PI producer (isolate 1B) was used for further experiments and the isolate was named as $1_{\mathrm{B}} \mathrm{PI}$. The same experiment was carried out separately for the selected isolate in the media with and without protease inhibitor. Casein hydrolysis was found evident in the media without protease inhibitor (Fig. 4a). Casein hydrolysis was inhibited due to the presence of protease inhibitor in the other plate (Fig. 4b).

\section{Purification of protease inhibitor}

The crude PI samples were purified using standard Ammonium sulphate precipitation. Protein precipitated was collected by centrifugation and further dialyzed against $0.01 \mathrm{M}$ phosphate buffer ( $\mathrm{pH} 7.5$ ), in order to remove the ammonium sulphate from the precipitate (Fig. 5). The purified fractions finally collected in the vials were presented in Fig. 6. Each purified vials are used for secondary protease inhibitor assay.

\section{Secondary Protease inhibitor (PI) assay}

The protease inhibitory activity of isolates $\mathrm{B}_{1} \mathrm{PI}, \mathrm{B}_{2} \mathrm{PI}$ and $\mathrm{B}_{3} \mathrm{PI}$ was analyzed after reacting with protease based trypsin substrate. Among the PI fractions of three bacterial isolates, $\mathrm{B}_{2} \mathrm{PI}$ expressed significant inhibitory activity of $77.5 \pm 0.25 \%$. $\mathrm{B}_{1} \mathrm{PI}$ and $\mathrm{B}_{3} \mathrm{PI}$ also inhibited trypsin action of upto $27.3 \pm 0.57 \%$ and $32.2 \pm 0.86 \%$ respectively. As the difference in the inhibitory activity was highly evident among the three isolates, this assay was considered as the confirmatory method (Table-2). As the isolate $\mathrm{B}_{2} \mathrm{PI}$ showed maximum 
inhibitory activity in the secondary PI assays, the antibacterial activity was carried out using the PI fractions of the same isolate.

\section{Antibacterial activity of PI against biofilm producing bacteria}

Antibacterial activity of the $\mathrm{B}_{2} \mathrm{PI}$ protease inhibitor fractions were assessed against the biofilm producing organisms on MHA plates compared with a standard fluoroquinolone drug ofloxacin. The quinolone drug was already proved to be effective against organisms associated with biomaterial centered infections caused due to biofilm producers. During the analysis, the zone of inhibition measured in millimetres for PI and ofloxacin was calculated in triplicates and presented in Mean \pm Std deviation. The most significant biofilm producing organisms Escherichia coli and Staphylococcus aureus were observed to be highly susceptible to the inhibitor fractions. Escherichia coli and Staphylococcus aureus exhibited inhibitory zones of $22.3 \pm 1.04 \mathrm{~mm}$ and $20.2 \pm 0.25 \mathrm{~mm}$. Staphylococcus epidermidis and Klebsiella pneumoniae showed inhibitory zones of $20.2 \pm 0.25 \mathrm{~mm}$ and $19.6 \pm 0.57 \mathrm{~mm}$. As expected drug resistant Pseudomonas aeruginosa expressed less inhibitory activity $(18.3 \pm 0.57 \mathrm{~mm})$ than the other test organisms. Similar difference in the susceptible pattern was evident for the fluoroquinolone ofloxacin (Table-3).

The obtained results revealed that the protease inhibitor fractions increase the therapeutic effect resulting in greater inhibitory zones against the test organisms. The mode of action of PI on the process of enzyme production was reported. Protease inhibitors control the action of proteases that are indispensable for the growth and development of the organism. Protease inhibitors were considered to inhibit the growth of protease producing microorganism. It has been shown that protease inhibitors participate in the defense response of pathogens. Recently, protease inhibitors have received new interest due to their potent ability to prevent carcinogenesis in a wide variety of in vivo and in vitro systems (Jin-Young et al., 2009).

\section{Anti-biofilm assay of PI against biofilm producers}

To determine the effect of PI on protease producing bacteria which are associated with the biofilm production was studied using sustained inhibition biofilm assay. In this assay, protease inhibitors added during the 90-minute adherence and 24-hour growth steps prevented the biofilm formation of all test organisms in the microtitre plate well surfaces. Antibiotic resistant characters of the biofilm producing bacteria always remain as a common problem in treatment of biofilm associated infections. $\mathrm{B}_{2} \mathrm{PI}$ protease inhibitor fractions 
showed sustained biofilm inhibition on all the test organisms in terms of minimal biofilm inhibitory concentration. Escherichia coli and Staphylococcus aureus exhibited $31.2 \mu 1 / \mathrm{ml}$ of MBIC. Klebsiella pneumoniae, Pseudomonas aeruginosa and Staphylococcus epidermidis showed $62.4 \mu 1 / \mathrm{ml}$ of MBIC (Table-4). The effect of PI concentrations was found comparatively closer to the MBIC of fluoroquinolone ofloxacin $(31.2 \mu 1 / \mathrm{ml})$.

The ability of test organisms to form biofilms may challenge the treatment protocol especially resistant to all classes of antibacterial drugs used currently in health care systems. The results established in the present research suggested that proteolysis is important for the maintenance of the biofilm structure since protease inhibitors contribute to the prevention and disruption of these biofilms (Lohse et al., 2017).

Proteases may play several different roles in bacterial biofilm formation, an idea supported by the fact that proteases are dynamically expressed throughout the course of biofilm formation. Proteases like serine and aspartyl types are highly up-regulated at certain stages of biofilm formation, which are known to mediate adhesion of bacterial cells to surface. Proteases may also contribute to the breakdown and acquisition of nutrients, the processing of molecules important for biofilm formation. Although the involvement of secreted proteases in biofilm formation is a relatively new concept, there is some precedent for this idea in bacterial biofilms, where extracellular proteases were found to be involved in the processing of adhesion molecules during biofilm formation of bacterial species (Fox et al., 2015).

As the results in the present research showed promising antibacterial and anti-biofilm activity, the protease inhibitor from the microbial mat isolate $\mathrm{B}_{2} \mathrm{PI}$ would be an effective alternative to most of the commercial antibiotics in future. It was reported that PI could also act synergistically with other classes of antibacterial drugs, antifungal drugs (Lohse et al., 2020) and antiviral drugs (Tsang and Hong, 2009).

\section{ACKNOWLEDGEMENT}

I thank my research supervisor Dr.V.Shanmugharaj, Head, Department of Biotechnology, for his immense and continuous guidance throughout the research work.

\section{CONFLICT OF INTEREST}

Authors have no conflict of interest to declare 
Table-1: Screening the isolates for PI production using Protease inhibitor assay

\begin{tabular}{|c|c|c|c|}
\hline S. No. & Isolates & Observation & PI assay \\
\hline 1 & 1A & No casein hydrolysis & PI producing isolate \\
\hline 2 & 1B & No casein hydrolysis & PI producing isolate \\
\hline 3 & $1 \mathrm{C}$ & casein hydrolysis & Non PI producing isolate \\
\hline 4 & $1 \mathrm{D}$ & casein hydrolysis & Non PI producing isolate \\
\hline 5 & $1 \mathrm{E}$ & casein hydrolysis & Non PI producing isolate \\
\hline 6 & $1 \mathrm{~F}$ & casein hydrolysis & Non PI producing isolate \\
\hline
\end{tabular}

Table-2: Secondary Protease inhibitor (PI) assay of the isolates

\begin{tabular}{|c|c|c|}
\hline S. No. & Isolates & Trypsin inhibition (\%) \\
\hline 1 & $\mathrm{~B}_{1} \mathrm{PI}$ & $77.5 \pm 0.25$ \\
\hline 2 & $\mathrm{~B}_{2} \mathrm{PI}$ & $27.3 \pm 0.57$ \\
\hline 3 & $\mathrm{~B}_{3} \mathrm{PI}$ & $32.2 \pm 0.86$ \\
\hline
\end{tabular}

*Mean \pm Standard deviation

Table-3: Antibacterial activity of PI against biofilm producing bacteria

\begin{tabular}{|c|c|c|c|}
\hline \multirow{2}{*}{ S. No } & \multirow{2}{*}{ Test organism } & \multicolumn{2}{|c|}{ Zone of inhibition (mm) } \\
\cline { 3 - 4 } & & PI & STD (Ofloxacin) \\
\hline 1 & Escherichia coli & $22.3 \pm 1.04$ & $24.3 \pm 1.08$ \\
\hline 2 & Klebsiella pneumoniae & $19.6 \pm 0.57$ & $23.6 \pm 0.25$ \\
\hline 3 & Pseudomonas aeruginosa & $18.3 \pm 0.57$ & $22.1 \pm 0.86$ \\
\hline 4 & Staphylococcus aureus & $21.6 \pm 1.08$ & $23.3 \pm 1.04$ \\
\hline 5 & Staphylococcus epidermidis & $20.2 \pm 0.25$ & $24.6 \pm 0.57$ \\
\hline
\end{tabular}

*Mean \pm Standard deviation

Table-4: Anti-biofilm assay of PI against biofilm producers

\begin{tabular}{|c|c|c|c|}
\hline \multirow{2}{*}{ S. No } & \multirow{2}{*}{ Test organism } & \multicolumn{2}{|c|}{ MBIC values $(\boldsymbol{\mu l} / \mathbf{m l})$} \\
\cline { 3 - 4 } & Escherichia coli & $\begin{array}{c}\mathbf{B}_{2} \text { PI protease } \\
\text { inhibitor }\end{array}$ & $\begin{array}{c}\text { Ofloxacin } \\
\text { (Antibiotic) }\end{array}$ \\
\hline 1 & Klebsiella pneumoniae & 31.2 & 31.2 \\
\hline 2 & Pseudomonas aeruginosa & 62.4 & 31.2 \\
\hline 3 & Staphylococcus aureus & 31.2 & 31.2 \\
\hline 4 & Staphylococcus epidermidis & 62.4 & 31.2 \\
\hline 5 & & & 31.2 \\
\hline
\end{tabular}




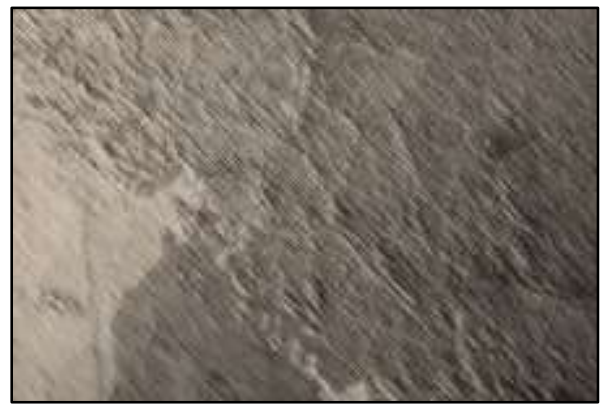

Fig. 1a Microbial mat-1

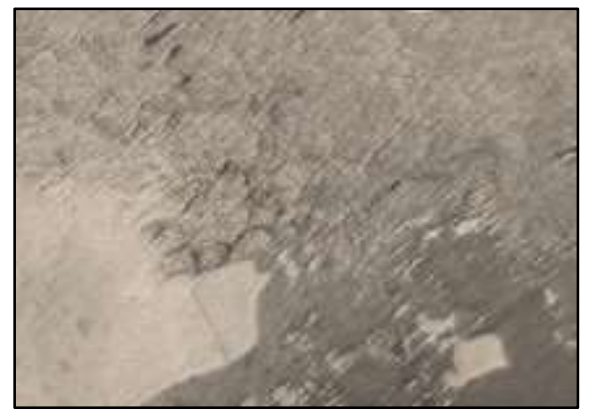

Fig. 1b Microbial mat-2

Fig. 1: Selection of Microbial mat

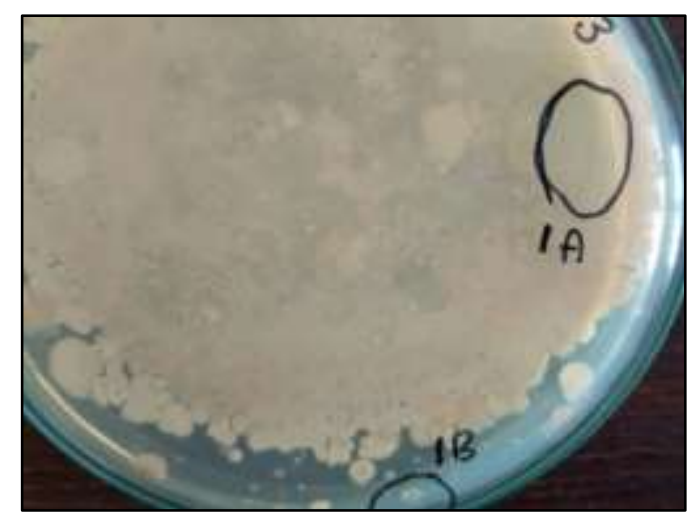

Fig. 2a

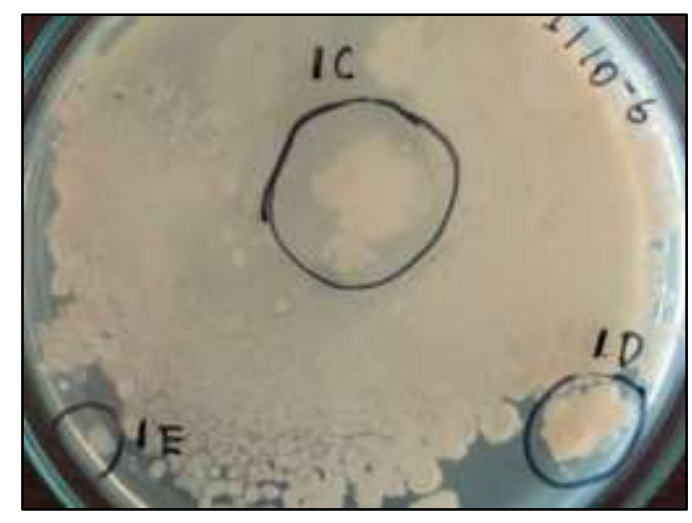

Fig. $2 b$

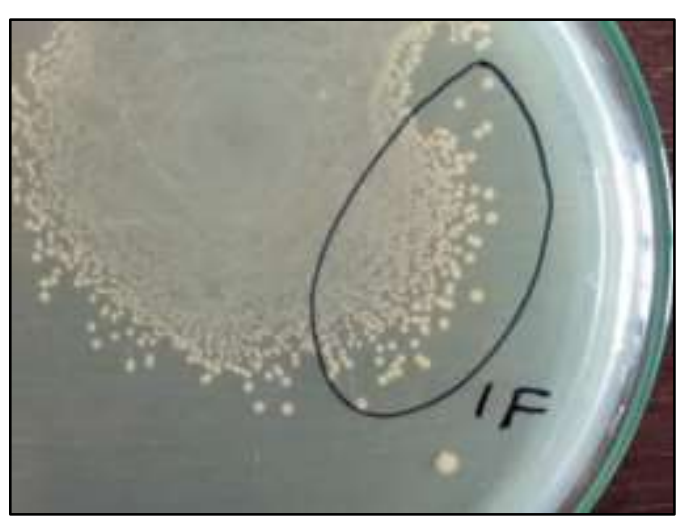

Fig. 2c

Fig. 2: Isolation of bacteria from microbial mats 


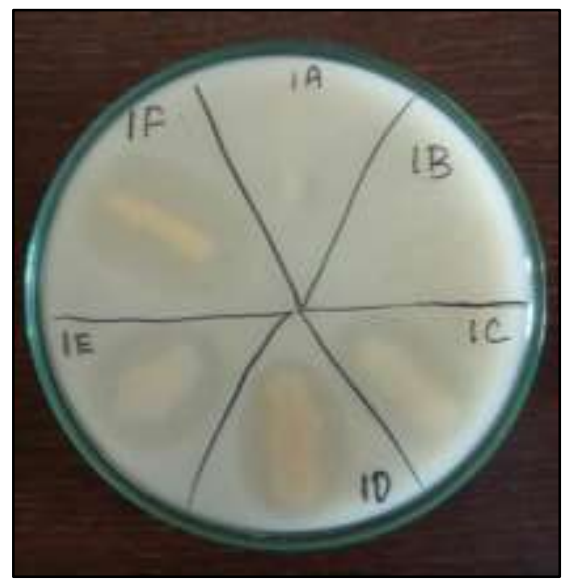

(1A and 1B are Protease inhibitor producers - No casein hydrolysis)

(1C, 1D, 1E and 1F are NOT protease inhibitor producers - casein hydrolysis is evident)

Fig. 3: Screening the isolates for PI production using Protease inhibitor assay

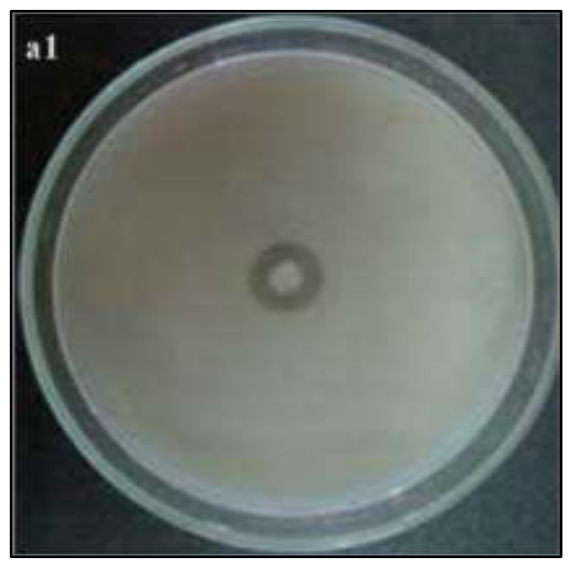

Fig. 4a: Casein hydrolysis evident (absence of PI)

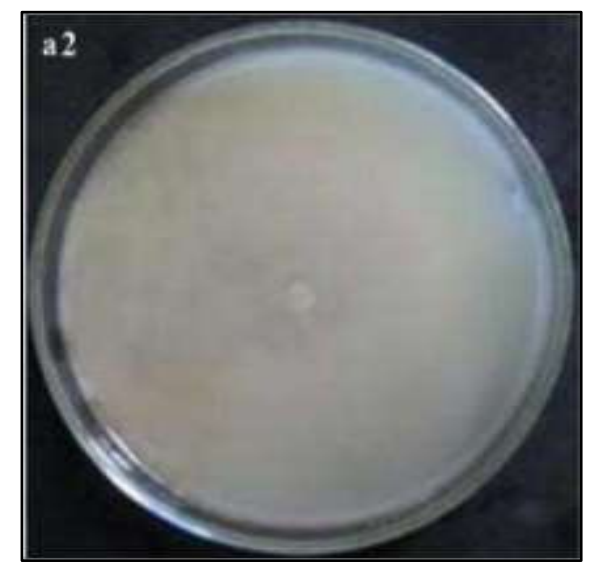

Fig. 4b: Inhibition of casein hydrolysis (presence of PI)

Fig.4: Protease inhibitor assay of microbial mat isolate (1BPI) 


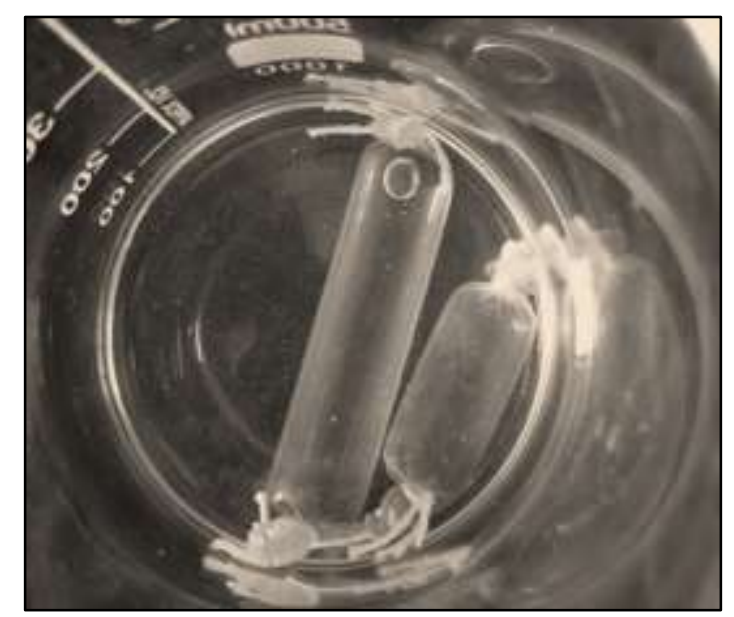

Fig. 5: Dialysis - Purification of Protease inhibitor

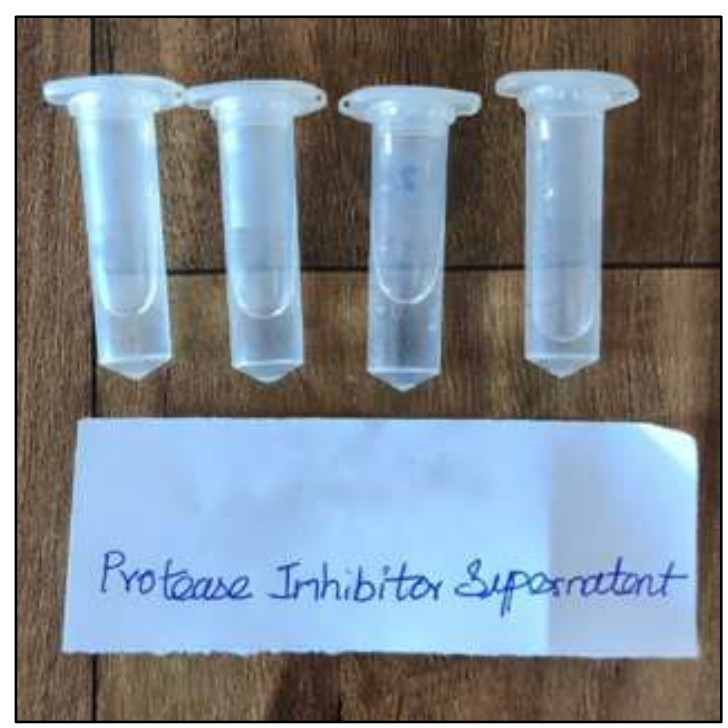

Fig. 6: Purified fractions of Protease inhibitor 


\section{REFERENCE}

1. Charlesworth JC, Cara Watters, Hon Lun Wong, Pieter T Visscher, Brendan P Burns. Isolation of novel quorum-sensing active bacteria from microbial mats in Shark Bay Australia, FEMS Microbiology Ecology, 2019; 95(4):121-126.

2. Donlan RM. Biofilm formation: a clinically relevant microbiological process. Clin Infect Dis, 2001; 33:1387-1392.

3. Fox EP, Bui CK, Nett JE, Hartooni N, Mui MC, Andes DR, Nobile CJ, Johnson AD. An expanded 551 regulatory network temporally controls Candida albicans biofilm formation. Mol Microbiol, 2015; 96:1226-1239.

4. Gulati M, Lohse MB, Ennis CL, Gonzalez RE, Perry AM, Bapat P, Arevalo AV, Rodr iguez DL, Nobile CJ. InVitro Culturing and Screening of Candida albicans Biofilms. Curr Protoc Microbiol, 2018; 50:60-67.

5. Hamilton SC, Farchaus JW, and Davis MC. DNA polymerases as engines for biotechnology. Biotechniques, 2001; 31:370-376.

6. Imada C. Enzyme inhibitors of marine microbial origin with pharmaceutical importance. Mar Biotechnol, 2004; 6:193-198.

7. Jin-Young K, Seong-Cheol P, Indeok H, Hyeonsook C, Jae-Woon N, Kyung-Soo $\mathrm{H}$ and Yoonkyung P. Protease Inhibitors from Plants with Antimicrobial Activity. Int J Mol Sci. 2009; 10(6):2860-2872.

8. Leung D, Abbenante D, and Fairlie G. Protease inhibitors: Current status and future prospects. J. Med. Chem, 2000; 43:305-341.

9. Lohse MB, Gulati M, Arevalo AV, Fishburn A, Johnson AD, Nobile CJ. Assessment and optimizations of Candida albicans in vitro biofilm assays. Antimicrob Agents Chemother 2017; 61: 749-756.

10. Madigan MT, Jung DO, Woses CR, Achenbach LA. Rhodoferax antarcticus sp. A Moderately Psychrophilic Purple Non-sulfur Bacterium Isolated from an Antarctic Microbial Mat. Arch. Microbiol, 2000; 173(4): 269-277.

11. Prasad R, Shah AH, Rawal MK. Antifungals: Mechanism of Action and Drug Resistance. Adv Exp Med Biol, 2016; 8:327-349. 
12. Robert F, Nardy L and Roberts TH. Serpin protease inhibitors in plant biology. Physiologia Plantarum, 2012; 145, 95-102.

13. Sabotic $\mathbf{J}$ and Kos J. Microbial and fungal protease inhibitors - current and potential applications. Appl Microbiol Biotechnol, 2012; 93, 1351-1375.

14. Sakata K, Yajima H, Tanaka K, Sakamoto Y, Yamamoto K, Yoshida A, Dohs. Erythromycin inhibits the production of elastase by Pseudomonas aeruginosa without affecting its proliferation in vitro. Am Rev Respir Dis, 1993; 148: 1061-1065.

15. Skrbec D, Romeo D. Inhibition of Candida albicans secreted aspartic protease by a novel series of peptidomimetics, also active on the HIV-1 protease. Biochem Biophys Res Commun, 2002; 297:1350-1353.

16. Tsang CSP, Hong I. HIV protease inhibitors differentially inhibit adhesion of Candida albicans 531 to acrylic surfaces. Mycoses, 2009; 53:488-494.

17. Turk B. Targeting proteases: successes, failures and future prospects. Nat Rev Drug Discov 2006; 5, 785-799.

18. Wahyudi AT, Qatrunnada, Mubarik NR. Screening and Characterization of Protease Inhibitors from Marine Bacteria Associated with Sponge Jaspis sp. Hayati Journal of Biosciences. 2010; 17(4):173-178.

19. Wong L, Smith DL, Visscher PT. Niche differentiation of bacterial communities at a millimeter scale in Shark bay microbial mats Nature, 2015; 5: 156-160. 